\title{
Electrodeposition of amorphous molybdenum sulfide thin film for electrochemical hydrogen evolution reaction
}

\author{
Lina Zhang, Liangliu Wu, Jing Li and Jinglei Lei (i)
}

\begin{abstract}
Amorphous molybdenum sulfide $\left(M_{\mathrm{O}}\right.$ ) is a highly active noble-metal-free electrocatalysts for the hydrogen evolution reaction (HER). The MoS $x$ was prepared by electrochemical deposition at room temperature. Low-cost precursors of $\mathrm{Mo}$ and $\mathrm{S}$ were adopted to synthesize thiomolybdates solution as the electrolyte. It replaces the expensive $(\mathrm{NH})_{2} \mathrm{MoS}_{4}$ and avoid the poison gas $\left(\mathrm{H}_{2} \mathrm{~S}\right)$ to generate or employ. The $\left(\mathrm{MoO}_{2} \mathrm{~S}_{2}\right)^{2-}$, $\left(\mathrm{MoOS}_{3}\right)^{2-}$ and $\left(\mathrm{MoS}_{4}\right)^{2-}$ ions were determined by UV-VIS spectroscopy. The electrodeposition of $M_{0} S_{x}$ was confirmed with XRD, XPS and SEM. The electrocatalyst activity was measured by polarization curve. The electrolyte contained $\left(\mathrm{MoO}_{2} \mathrm{~S}_{2}\right)^{2-}$ ion and $\left(\mathrm{MoOS}_{3}\right)^{2-}$ ion electrodeposit the MoS thin film displays a relatively high activity for HER with low overpotential of $211 \mathrm{mV}$ at a current density of $10 \mathrm{~mA} \mathrm{~cm}^{-2}$, a relatively high current density of $21.03 \mathrm{~mA} \mathrm{~cm}^{-2}$ at $\eta=250 \mathrm{mV}$, a small Tafel slope of $55 \mathrm{mV} \mathrm{dec}^{-1}$. The added sodium dodecyl sulfate (SDS) can efficient improve the stability of the MoS $\mathrm{S}_{\mathrm{x}}$ ilm catalyst.
\end{abstract}

Keywords: Thiomolybdates solution, Amorphous molybdenum sulfide, Buffer solution, Electrodeposition, HER

\section{Introduction}

Hydrogen is a cleaner and sustainable energy, and it is one of the promising alternative energy carriers $[1,2]$. Electrochemical water splitting is attractive methods for hydrogen evolution [3-5]. An important problem for this method is seeking highly catalytic active electrocatalysts for hydrogen evolution reaction. In this regard, various efficient electrocatalysts materials, including Pt and other noble metals were investigated. However, high cost of Pt or other noble metals impede their widespread application $[6,7]$.

The employment of catalysts should have greatly highly catalytic active, low-cost, and earth-abundant non-noble metal. Recently, molybdenum sulfide is found to be an active HER catalyst, and it is useful for acidic HER condition [8-20]. While amorphous molybdenum shows highly catalytic activity at the unsaturated sulfur atoms present over the entire surface $[11,13,21-25]$. In the previous

\footnotetext{
*Correspondence: leijlei@163.com

School of Chemistry and Chemical Engineering, Chongqing University,
}

Chongqing 400044, People's Republic of China research, the most promising method of preparing the amorphous materials is cathodic reduction of an aqueous solution of ammonium tetrathiomolybdate $\left((\mathrm{NH})_{2} \mathrm{MoS}_{4}\right)$. Some researchers used the commodity $\left((\mathrm{NH})_{2} \mathrm{MoS}_{4}\right)[13$, $21,25-27]$, however, the commodity $\left((\mathrm{NH})_{2} \mathrm{MoS}_{4}\right)$ is highly expensive, therefore, some researchers synthesize the $\left((\mathrm{NH})_{2} \mathrm{MoS}_{4}\right)$ solution [28-30]. The methods for preparing of ammonium tetrathiomolybdate $\left(\left(\mathrm{NH}_{4}\right)_{2}\left(\mathrm{MoS}_{4}\right)\right)$ species are almost identical to Krüss [29], and the methods was improved by John W. McDonald's group [30] for the preparation of $\left(\mathrm{NH}_{4}\right)_{2}\left(\mathrm{MoO}_{2} \mathrm{~S}_{2}\right),\left(\mathrm{NH}_{4}\right)_{2}\left(\mathrm{MoOS}_{3}\right)$ and $\left(\mathrm{NH}_{4}\right)_{2}\left(\mathrm{MoS}_{4}\right)$. The synthesis involves the exhaustive treatment by $\mathrm{H}_{2} \mathrm{~S}$ gas of molybdate solution in concentrated $\mathrm{NH}_{4} \mathrm{OH}$. This method can easy to obtain the $\left(\mathrm{NH}_{4}\right)_{2}\left(\mathrm{MoS}_{4}\right)$, however, a steady stream of $\mathrm{H}_{2} \mathrm{~S}$ was employed. Ponomarev et al. [28] prepared the tetrathiomolybdate solution utilized a chemical reaction route. To a mixture solution of $5 \mathrm{mmol} \mathrm{L}{ }^{-1} \mathrm{Na}_{2} \mathrm{MoO}_{4}$ and excess $\mathrm{Na}_{2} \mathrm{~S}$ was added hydrochloric acid with stirring until a $\mathrm{pH}$ of 8.0 was attained. During this process, large amount of $\mathrm{H}_{2} \mathrm{~S}$ gas was generated. 
In this work, we further improved the approaches of synthesis of thiomolybdates solution. $\left(\mathrm{NH}_{4}\right)_{6} \mathrm{Mo}_{7} \mathrm{O}_{24} \cdot 4 \mathrm{H}_{2} \mathrm{O}$ and $\mathrm{Na}_{2} \mathrm{~S} \cdot 9 \mathrm{H}_{2} \mathrm{O}$ were employed as the precursors of $\mathrm{Mo}$ and $\mathrm{S}$, respectively. The ammonium chloride buffer solution $(\mathrm{pH}=8)$ replaced the hydrochloric acid to make the $\mathrm{pH}$ of the solution to 8 . This method does not produce a large amount of $\mathrm{H}_{2} \mathrm{~S}$ gas due to excessive local acid concentration. And it is very simple, the process is easy to control and is mild. Additionally, the precursor materials are economic, especially, the prepared thiomolybdates solution has great stability. The synthesized thiomolybdates solution as the electrolyte, employ the electrochemical deposition of amorphous molybdenum sulfide thin film for electrochemical hydrogen evolution. The HER performance measurement result suggests the catalyst displayed high catalytic activity for hydrogen evolution reaction. Add a bit of surfactant into the electrolyte, the stability of the $\mathrm{MoS}_{\mathrm{x}}$ film has effectively improved.

\section{Materials and methods Materials}

Hexaammonium heptamolybdate tetrahydrate $\left(\left(\mathrm{NH}_{4}\right)_{6} \mathrm{Mo}_{7} \mathrm{O}_{24} \cdot 4 \mathrm{H}_{2} \mathrm{O}, \geq 99.0 \%\right)$ was used as the Mo precursor. Sodium sulfide nonahydrate $\left(\mathrm{Na}_{2} \mathrm{~S} \cdot 9 \mathrm{H}_{2} \mathrm{O}\right.$, $\geq 98.0 \%$ ) was used as the $\mathrm{S}$ precursor. Ammonium chloride $\left(\mathrm{NH}_{4} \mathrm{Cl}, \geq 99.5 \%\right)$, ammonia solution $\left(\mathrm{NH}_{3}\right.$, 25-28\%), sulfuric acid $\left(\mathrm{H}_{2} \mathrm{SO}_{4}, 95-98 \%\right)$, hydrochloric acid ( $\mathrm{HCl}, 36.0-38.0 \%)$, acetone $\left(\mathrm{CH}_{3} \mathrm{COCH}_{3}, \geq 99.5 \%\right)$, sodium dodecyl sulfate $\left(\mathrm{C}_{12} \mathrm{H}_{25} \mathrm{NaO}_{4} \mathrm{~S}, \geq 85.0 \%\right)$. All reagents were purchased and used as received.

UV-VIS spectrophotometer (TU-1810,Beijing). Scanning electron microscopy (SEM) combined with energy dispersive X-ray spectroscopic (EDS) images were taken with a TESCAN VEGA II LMU instrument. The phase compositions of the samples were identified using an X-ray diffractometer (XRD, X'pert PRO, PANalytical B.V., Holland) using $\mathrm{Cu} \mathrm{K \alpha}$ radiation $(0.15418 \mathrm{~nm})$. The electrodeposition and electrochemical measurements were carried out at room temperature in a three-electrode glass cell connected to an electrochemical workstation (CHI440A, chenghua, Shanghai). The surface chemical composition was analyzed by X-ray photoelectron spectroscopy (XPS, Thermoelectron ESCALAB 250, USA).

\section{Syntheses of thiomolybdates solution}

$\left(\mathrm{NH}_{4}\right)_{6} \mathrm{Mo}_{7} \mathrm{O}_{24} \cdot 4 \mathrm{H}_{2} \mathrm{O}(3.58 \mathrm{~g})$ was dissolved in $200 \mathrm{~mL}$ ammonium chloride buffer solution $(\mathrm{pH}=8)$. In a second container, $21.65 \mathrm{~g}$ of $\mathrm{Na}_{2} \mathrm{~S} \cdot 9 \mathrm{H}_{2} \mathrm{O}$ was added to $300 \mathrm{~mL}$ of ammonium chloride buffer solution $(\mathrm{pH}=8)$. These two solutions were mixed and transferred to a $500 \mathrm{~mL}$ beaker. Put the mixed solution beaker to the $\sim 90{ }^{\circ} \mathrm{C}$ water bath for $2 \mathrm{~h}$. After that, the black and red solution was transferred to a $500 \mathrm{~mL}$ flask. Once the solution is cooling down to the room temperature, then the deionized water is used to add the solution to the scale.

\section{Catalyst synthesis}

The substrate used titanium ingot $(11.28 \mathrm{~mm}$ diameter, $3.5 \mathrm{~mm}$ thick, purity $99.99 \%)$. Prior to the electrodeposition, the Ti substrate was carefully cleaned with mechanical polishing, acetone and $\mathrm{HCl}$ solution (9 $\mathrm{wt} \%$ ) in an ultrasound bath each for $5 \mathrm{~min}$, successively. And then it was washed with deionized water after each step. Polytetrafluoroethylene (PTFE) electrode sets with working area of $1 \mathrm{~cm}^{2} . \mathrm{MoS}_{\mathrm{x}}$ was deposited on Ti substrate by electrodeposition in a three-electrode setup. The PTFE electrode sets with treated $\mathrm{Ti}$ substrate as the working electrode, saturated calomel electrode (SCE) as the reference electrode, and a graphite board as the counter electrode. The synthesized thiomolybdates solution as the electrolyte. The electrodeposition adopted the method of chronopotentiometry $(\mathrm{CP})$.

\section{Spectroscopic characterization}

The thiomolybdates determination were conducted using the UV-VIS spectrophotometer of ref. 30 . Take $0.1 \mathrm{~mL}$ thiomolybdates solution and dilute to $100 \mathrm{~mL}$ for spectral detecting. The range of wavelength is from 190 to $600 \mathrm{~nm}$. The scan rate is $0.5 \mathrm{~nm} \mathrm{~s}^{-1}$.

\section{Electrochemical measurements}

Electrochemical measurements were carried out with a three-electrode configuration in which saturated calomel electrode as the reference electrode, a graphite board as the counter electrode. Linear sweep voltammetry (LSV) with a $5 \mathrm{mV} \mathrm{s}^{-1}$ scan rate was performed in $0.5 \mathrm{M} \mathrm{H}_{2} \mathrm{SO}_{4}$ electrolyte, which was purged with $\mathrm{N}_{2}$ gas for at least $30 \mathrm{~min}$ prior to the LSV measurements in order to remove any dissolved $\mathrm{O}_{2}$. LSV curves were measured fifth for each sample to verification of the system's chemical stability. The scan range from 0.00 to $-0.55 \mathrm{~V}$ vs. SCE (not $i R$ corrected). After the LSV measurements, the solution was stirred. The reference electrode was calibrated for the reversible hydrogen potential using platinum wire was working and counter electrodes in the electrolyte solution saturated with $\mathrm{H}_{2}$. In $0.5 \mathrm{M} \mathrm{H}_{2} \mathrm{SO}_{4}$, the potential was converted to the reversible hydrogen potential (RHE) reference electrode by $\mathrm{E}(\mathrm{vs} . \mathrm{RHE})=\mathrm{E}(\mathrm{vs}$. SCE) $+0.26 \mathrm{~V}$. The resistance (R) was tested by EIS. EIS measurements were carried out in the frequency range of $0.1 \mathrm{~Hz}$ to $10^{5} \mathrm{~Hz}$ under a hydrogen evolution voltage, which corresponds to the potential at $10 \mathrm{~mA} \mathrm{~cm}^{-2}$.

Electrochemical stability is an important parameter for viability of a HER catalyst. To investigate HER stability under electrocatalytic operation in the acidic 
environment, long-term potential cycling stability of the $\mathrm{MoS}_{\mathrm{x}}$ film was assessed by taking continuous cyclic voltammograms $(\mathrm{CV})$ between 0.0 and $-0.55 \mathrm{~V}$ vs. saturated calomel electrode (not $i R$ corrected) at $100 \mathrm{mV} \mathrm{s}^{-1}$.

\section{Results and discussion Electrolyte}

Thiomolybdates solutions were synthesized in the buffer solutions containing different concentrations of ammonium chloride. The ammonium chloride concentration is from 0.1 to $0.5 \mathrm{M}$. Different ammonium chloride concentration results in the different color of the thiomolybdates solutions. The thiomolybdates solutions color was changed from light yellow to dark red, along with the increasing of the ammonium chloride concentration. The different color of the thiomolybdates solutions attribute to the different thiomolybdates species. The various thiomolybdates can be determined by UV-VIS Spectroscopy [30]. The actual UV-VIS Spectra of the thiomolybdates solutions are shown in Fig. 1. Peak position and molar absorptivities are provided in Table 1.

By comparing the results from the previously reports [30], it can be concluded that to adjust the ammonium chloride concentration of the ammonium chloride buffer solution can syntheses the various thiomolybdates solutions. With the concentration of ammonium chloride increases, the thio-degree rises up. In the $0.2 \mathrm{M} \mathrm{NH}_{4} \mathrm{Cl}$ buffer solution, the molar absorptivities for the peaks at 292.0 and $395.5 \mathrm{~nm}$, the result clear support for the $\left(\mathrm{MoO}_{2} \mathrm{~S}_{2}\right)^{2-}$ ion was synthesized. In the $0.3 \mathrm{M} \mathrm{NH}_{4} \mathrm{Cl}$ buffer solution, the peak at $466 \mathrm{~nm}$ started to appear, this result supports for the $\left(\mathrm{MoOS}_{3}\right)^{2-}$ ion initial synthesis. In the solutions with ammonium chloride concentration of $0.4 \mathrm{M}$ and $0.5 \mathrm{M}$, the intensity of the peak at

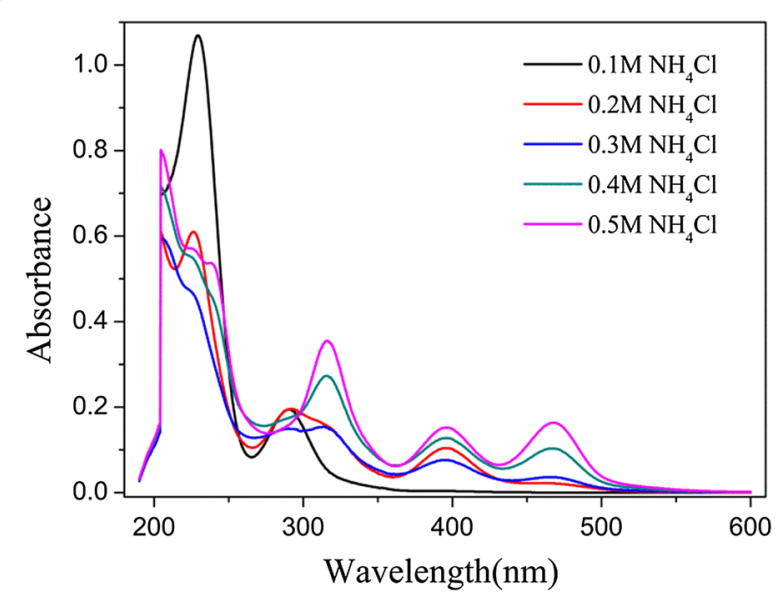

Fig. 1 Electronic spectra of thiomolybdates solutions with different concentration of ammonium chloride in the ammonium chloride buffer solution
Table 1 Spectral data for thiomolybdates solutions

\begin{tabular}{ll}
\hline $\begin{array}{l}\text { Concentration of ammonium } \\
\text { chloride }\end{array}$ & UV-VIS $^{\mathbf{a}}$ \\
\hline $0.1 \mathrm{M}$ & $229.5(1.069), 290.5(0.195)$ \\
$0.2 \mathrm{M}$ & $226.5(0.610), 292.0(0.196), 395.5(0.104)$ \\
$0.3 \mathrm{M}$ & $290.5(0.150), 313.0(0.154)$, \\
& $396.0(0.076), 466.00(0.036)$ \\
$0.4 \mathrm{M}$ & $315.5(0.273), 396.0(0.128), 467.0(0.103)$ \\
$0.5 \mathrm{M}$ & $316.5(0.355), 396.0(0.152), 468.0(0.163)$ \\
\hline
\end{tabular}

a Peak positions in $\mathrm{nm}$ with molar absorbance in parentheses

$467.0 \mathrm{~nm}$ is becoming stronger, and the intensity of the peaks at 396.0 and $467.0 \mathrm{~nm}$ was very close. From the previously reports [30], the purity $\left(\mathrm{MoS}_{4}\right)^{2-}$ ion exhibits a very strong absorption at $467 \mathrm{~nm}$ but non at $395 \mathrm{~nm}$. In Fig. 1, according to the spectra of the $0.4 \mathrm{M} \mathrm{NH}_{4} \mathrm{Cl}$ and the $0.5 \mathrm{M} \mathrm{NH}_{4} \mathrm{Cl}$ buffer solution, the peaks at 396.0 and $467.0 \mathrm{~nm}$ are simultaneous occurrence. From these results it is clear that the solution contains both of the $\left(\mathrm{MoOS}_{3}\right)^{2-}$ ion and $\left(\mathrm{MoS}_{4}\right)^{2-}$ ion, and the content of $\left(\mathrm{MoS}_{4}\right)^{2-}$ in the $0.5 \mathrm{M} \mathrm{NH}_{4} \mathrm{Cl}$ buffer solution is more than in the $0.4 \mathrm{M} \mathrm{NH}_{4} \mathrm{Cl}$ buffer solution. The ammonium chloride concentration determines the buffer capacity of buffer solution. The results suggest both of the $0.4 \mathrm{M}$ and $0.5 \mathrm{M} \mathrm{NH}_{4} \mathrm{Cl}$ buffer solution could synthesize the solution with the $\left(\mathrm{MoOS}_{3}\right)^{2-}$ ion and $\left(\mathrm{MoS}_{4}\right)^{2-}$ ion. And the two ions could to produce the molybdenum sulfide thin film under electrochemical deposition. We required the synthesized thiomolybdates solution as the electrolyte to electrodeposit of molybdenum sulfide thin film, and the molybdenum sulfide thin film could with relatively high HER performance.

\section{Characterization of $\operatorname{MoS}_{\mathbf{x}}$}

In the previous studies [13, 21, 25-27], they always employed the purity tetrathiomolybdate to prepare the $\mathrm{MoS}_{2}$ or $\mathrm{MoS}_{3}$. In this work, we applied the synthesized thiomolybdates solution as the electrolyte to electrodeposit of molybdenum sulfide thin film for electrochemical hydrogen evolution, and XRD (Additional file 1: Figure S1) analysis identified as amorphous molybdenum sulfides.

Figure 2 displays the detailed XPS scans for the Mo and $\mathrm{S}$ binding energies for the molybdenum sulfide thin film. The XPS spectra of molybdenum sulfide thin film are similar to those of known $\operatorname{MoS}_{\mathrm{x}}$ samples [13, 22]. The molybdenum sulfide thin film exhibits two characteristic peaks at 229.4 and $232.5 \mathrm{eV}$, attributed to the Mo $3 \mathrm{~d}_{5 / 2}$ and $3 \mathrm{~d}_{3 / 2}$ binding energies for $\mathrm{Mo}^{4+}[11,13$, 22]. The observation of Mo $3 \mathrm{~d}_{5 / 2}$ and $3 \mathrm{~d}_{3 / 2}$ binding energies at 230.5 and $234.1 \mathrm{eV}$ suggests the presence of $\mathrm{Mo}^{5+}$ 

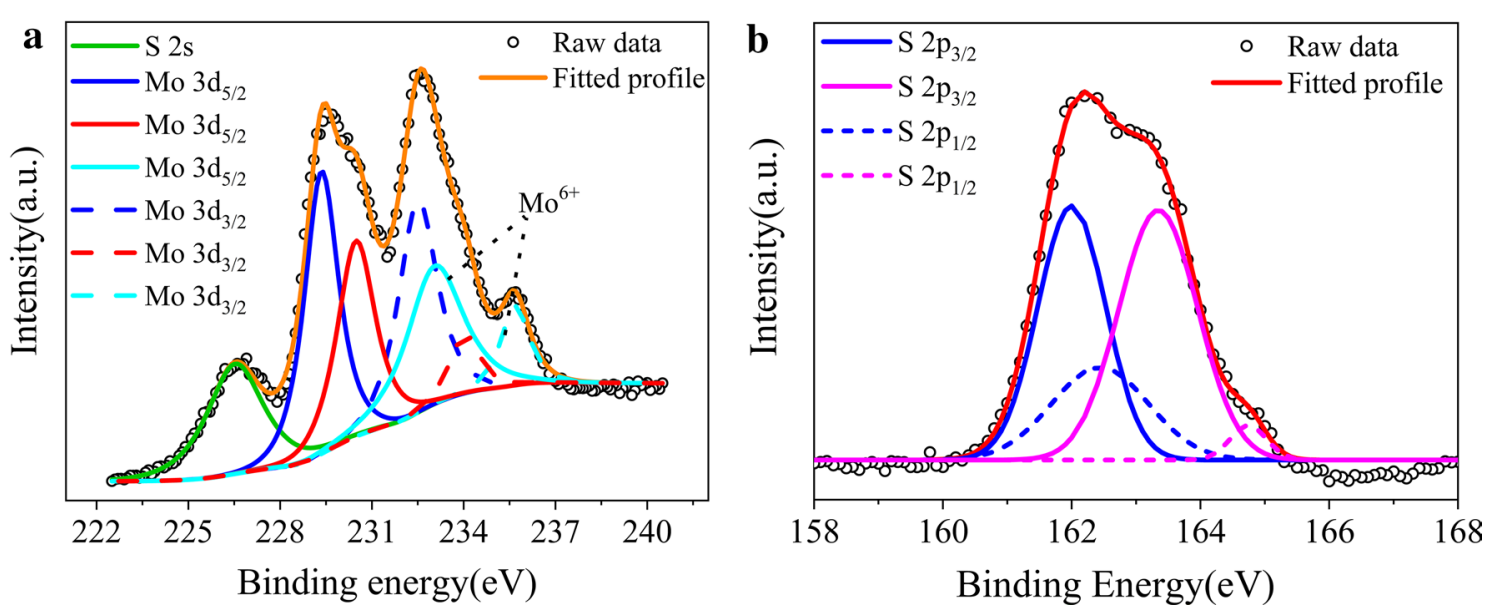

Fig. 2 XPS spectra for $\mathrm{MoS}_{x}$ film grown by chronopotentiometry negative electrodeposition at $2 \mathrm{~mA} \mathrm{~cm}{ }^{-2}$. a Mo $3 \mathrm{~d}$ and S $2 \mathrm{~s}$ region; experimental data (circle line), fitting envelope (orange line), $\mathrm{Mo}^{4+}$ (blue line), $\mathrm{Mo}^{5+}$ (red line), $\mathrm{Mo}^{6+}$ (light blue line), $\mathrm{S}^{2-} 2 \mathrm{~s}$ (green line), b S 2p region; experimental data (circle line), fitting envelope (orange line), $\mathrm{S}_{2}{ }^{2-}$ (purple line), $\mathrm{S}^{2-}$ (blue line)

ions $[11,13,22]$. The peaks, corresponding to the Mo $3 \mathrm{~d}_{5 / 2}$ and $3 \mathrm{~d}_{3 / 2}$ orbital of $\mathrm{Mo}^{6+}$ are observed at 233.1 and $235.7 \mathrm{eV}$. Meanwhile, the $\mathrm{S} 2 \mathrm{p}_{1 / 2}$ and $2 \mathrm{p}_{3 / 2}$ energies at 162.0 and $162.4 \mathrm{eV}$ demonstrate the existence of bridging $\mathrm{S}^{2-}$. And the $\mathrm{S} 2 \mathrm{p}_{1 / 2}$ and $2 \mathrm{p}_{3 / 2}$ energies at 163.3 and $164.7 \mathrm{eV}$ indicate the existence of bridging $\mathrm{S}_{2}{ }^{2-}$ or $\mathrm{S}^{2-}$. The binding energies of Mo and $\mathrm{S}$, proving that the structure is amorphous molybdenum sulfides, labeled as $\mathrm{MoS}_{\mathrm{x}}$ $[22,31]$.

\section{Electrodeposition MoS $_{x}$}

The electrodeposition method for amorphous molybdenum sulfide thin film was CP. The deposition current density was $2 \mathrm{~mA} \mathrm{~cm}^{-2}$, the deposition temperature was $20.0{ }^{\circ} \mathrm{C}$, the deposition time was $900 \mathrm{~s}$, and accompanied with stirring during the deposition process. The electrolyte used the synthesized thiomolybdates solutions with $0.2 \mathrm{M}, 0.4 \mathrm{M}$ and $0.5 \mathrm{M}$ ammonium chloride, respectively. The samples named as S-0.2, S- 0.4 and S- 0.5 corresponding to the ammonium chloride concentration. The deposition curves (potential-time) are shown in Fig. 3a, and color film formed on the electrode (Inset in Fig. 3a).

\section{HER activities}

The HER catalytic activity of these molybdenum sulfide films as the catalyst was measured employing the standard three-electrode electrochemical configuration in $0.5 \mathrm{M} \mathrm{H}_{2} \mathrm{SO}_{4}$ electrolyte-aerated with $\mathrm{Ar}$, as described in "Materials and methods". The polarization curves (not $i R$ corrected) showing the normalized current density versus voltage ( $j$ versus $\mathrm{V}$ ) for the S- $0.2, \mathrm{~S}-0.4$ and $\mathrm{S}-0.5$ films along with Pt wire and Ti ingot samples, for comparison, are illustrated in Fig. 3b. As expected, Pt wire catalyst exhibits excellent HER performance, and their HER performances are summarized in Table 2. In contrast, S-0.2, S- -0.4 and S- 0.5 films produces $j$ of $10 \mathrm{~mA} \mathrm{~cm}^{-2}$ at $\eta$ of $319 \mathrm{mV}, 211 \mathrm{mV}$ and $270 \mathrm{mV}$, respectively. Further insight into the catalytic activity of $\mathrm{MoS}_{\mathrm{x}}$ samples were obtained by extracting the slopes from the Tafel plots shown in Fig. 3c. The corresponding Tafel slopes of the $\mathrm{MoS}_{\mathrm{x}}$ films are in the range of 55 to $87 \mathrm{mV} \mathrm{dec}{ }^{-1}$. The lowest Tafel slope of $\sim 55 \mathrm{mV}$ per decade was attained for the sample of S-0.4. This indicates the Volmer reaction is taking place, a process to convert protons into sorbed hydrogen atoms on the MoSx film surface, and this process becomes the rate-determining step in the HER mechanism [5, 32, 33]. Figure $3 \mathrm{~d}$ exhibits the ammonium chloride concentration dependent current densities at $\eta=150,200$ and $250 \mathrm{mV}$. The current densities at the optimal ammonium chloride concentration are 1.12, 7.50 and $21.03 \mathrm{~mA} \mathrm{~cm}^{-2}$ at $\eta=150,200$ and $250 \mathrm{mV}$, respectively. The optimal ammonium chloride concentration is $0.4 \mathrm{M}$. The sample of S-0.4 film displayed relative high catalytic activity for hydrogen evolution reaction, the overpotential is lower than many other reported acid-stable and earth-abundant HER electrocatalysts, including amorphous $\mathrm{MoS}_{3}\left(\sim 270 \mathrm{mV}\right.$ at $\left.10 \mathrm{~mA} \mathrm{~cm}{ }^{-2}\right)$ [11], amorphous $\operatorname{MoS}_{\mathrm{x}}$ film $\left(\sim 150 \mathrm{mV}\right.$ at $\left.0.4 \mathrm{~mA} \mathrm{~cm}{ }^{-2}\right)$ [21], amorphous molybdenum sulfide $(\sim 200 \mathrm{mV}$ at $\left.10 \mathrm{~mA} \mathrm{~cm}^{-2}\right)$ [23], electrodeposited $\mathrm{MoS}_{2}(\sim 440 \mathrm{mV}$ at $\left.10 \mathrm{~mA} \mathrm{~cm}{ }^{-2}\right)$ [24] and double-gyroid mesoporous $\mathrm{MoS}_{2}$ films $\left(\sim 235 \mathrm{mV}\right.$ at $\left.10 \mathrm{~mA} \mathrm{~cm}{ }^{-2}\right)$ [34] (More details of HER parameters of $\operatorname{MoS}_{x}$ and other literature values is listed in Table 3). 

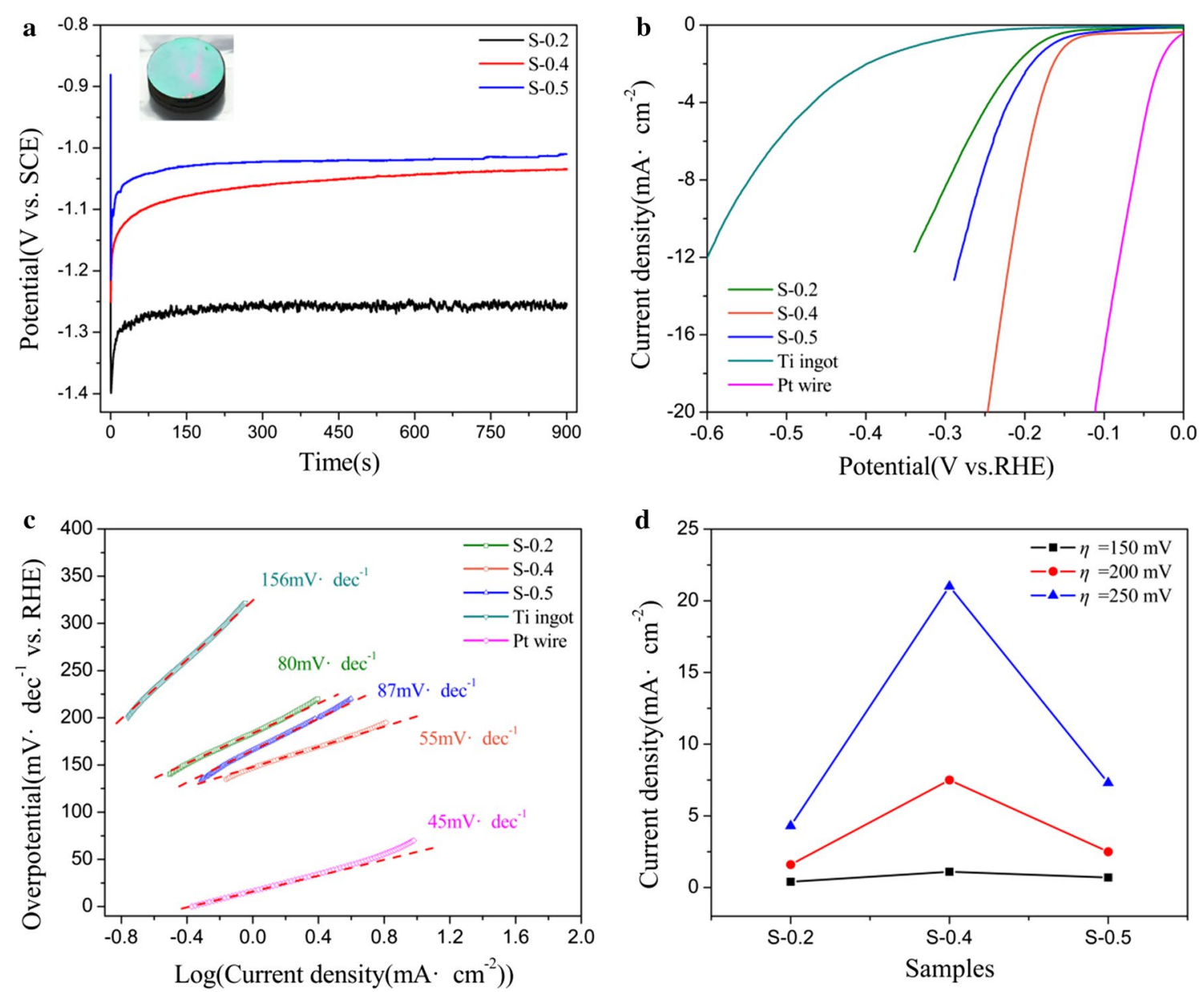

Fig. 3 a Chronopotentiometry during the deposition of molybdenum sulfide films, the samples named as S-0.2, S- 0.4 and S- 0.5 corresponding to the ammonium chloride concentration with $0.2 \mathrm{M}, 0.4 \mathrm{M}$ and $0.5 \mathrm{M}$, respectively. Inset: digital photo of an amorphous molybdenum sulfide film on Ti ingot. b Polarization curves for HER on bare Ti ingot and deposition on the Ti ingot of MoS films of S-0.2, S- 0.4 and S- 0.5 and a high-pure Pt wire, scan rate $=5 \mathrm{mV} \mathrm{s}^{-1}$. $\mathbf{c}$ Tafel plot for the various catalysts derived from $\mathbf{b}$. d Current densities curves at the overpotential of $150 \mathrm{mV}, 200 \mathrm{mV}$ and $250 \mathrm{mV}$, respectively

Table 2 Comparison of catalytic performance of different HER electrocatalysts in $0.5 \mathrm{M} \mathrm{H}_{2} \mathrm{SO}_{4}$

\begin{tabular}{|c|c|c|c|c|c|c|}
\hline Catalyst & $\begin{array}{l}\text { Exchange current } \\
\text { density }\left(\mu \mathrm{A} \mathrm{cm}^{-2}\right)\end{array}$ & $\begin{array}{l}j\left(\mathrm{~mA} \mathrm{~cm}^{-2}\right) \\
\eta=150 \mathrm{mV}\end{array}$ & $\begin{array}{l}j\left(\mathrm{~mA} \mathrm{~cm}^{-2}\right) \\
\eta=200 \mathrm{mV}\end{array}$ & $\begin{array}{l}j\left(\mathrm{~mA} \mathrm{~cm}^{-2}\right) \\
\eta=250 \mathrm{mV}\end{array}$ & $\begin{array}{l}\text { Overpotential } \\
\eta(\mathrm{mV} \mathrm{vs.} \mathrm{RHE)} \\
j=10 \mathrm{~mA} \mathrm{~cm}\end{array}$ & $\begin{array}{l}\text { Tafel slop } \\
\left(\mathrm{mV} \mathrm{dec}^{-1}\right)\end{array}$ \\
\hline Pt wire & 429.89 & 32.290 & 56.660 & - & 72 & 45 \\
\hline S-0.2 & 5.088 & 0.387 & 1.560 & 4.338 & 319 & 80 \\
\hline S-0.4 & 1.89 & 1.117 & 7.501 & 21.030 & 211 & 55 \\
\hline S-0.5 & 12.37 & 0.671 & 2.508 & 7.268 & 270 & 87 \\
\hline
\end{tabular}

Another important aspect utilized to evaluate the performance of an electrocatalyst is the long-term operating stability. Continuous cyclic voltammetry $(\mathrm{CV})$ in the cathodic potential window at a scan rate of $100 \mathrm{mV} \mathrm{s}^{-1}$ was performed on the films over 1000 cycles to investigate their long-term stability. Cathodic polarization curves were collected after 1000 cycles testing (Fig. 4) to investigation the current-density degradation compared with the initial polarization curve. In Fig. 4a, the cathodic polarization curves were corresponding to the sample of S-0.4. It is observed that the current density (without $i \mathrm{R}$ correction at overpotential of $250 \mathrm{mV}$ ) 
Table 3 HER parameters of $\operatorname{MoS}_{x}$ and other literature values

\begin{tabular}{|c|c|c|c|c|}
\hline Catalysts & $\begin{array}{l}\text { Exchange current } \\
\text { density }\left(\mu \mathrm{Acm}^{-2}\right)\end{array}$ & $j\left(\mathrm{~mA} \mathrm{~cm}{ }^{-2}\right)$ & $\begin{array}{l}\text { Overpotential } \\
\eta(\mathrm{mV} \text { vs. RHE) } \\
j=10 \mathrm{~mA} \mathrm{~cm}^{-2}\end{array}$ & $\begin{array}{l}\text { Tafel slop } \\
\left(\mathrm{mV} \mathrm{dec}^{-1}\right)\end{array}$ \\
\hline Amorphous MoS f film (this work) & 1.89 & $\begin{array}{l}21.030 \\
\eta=250 \mathrm{mV}\end{array}$ & 211 & 55 \\
\hline Amorphous $\mathrm{MoS}_{3}[11]$ & - & $\begin{array}{l}1.2 \sim 1.0 \\
\eta=200 \mathrm{mV}\end{array}$ & $\sim 270$ & $41 \sim 63$ \\
\hline Amorphous $\mathrm{MoS}_{3}$ [13] & - & - & 160 & 40 \\
\hline Amorphous $\mathrm{MoS}_{3}$-AE [25] & - & - & $\begin{array}{l}\sim 170 \mathrm{mV} \\
j=20 \mathrm{~mA} \mathrm{~cm}^{-2}\end{array}$ & - \\
\hline Amorphous $\mathrm{MoS}_{3}-\mathrm{CV}$ film [21] & 0.13 & $\begin{array}{l}0.4 \\
\eta=150 \mathrm{mV}\end{array}$ & $\begin{array}{l}200 \\
j=14 \mathrm{~mA} \mathrm{~cm}^{-2}\end{array}$ & 40 \\
\hline Amorphous molybdenum sulfide [23] & - & - & $\sim 200$ & $53 \sim 65$ \\
\hline Electrodeposited $\mathrm{MoS}_{2}[24]$ & - & $\begin{array}{l}0.34 \\
\eta=200 \mathrm{mV}\end{array}$ & $\sim 440$ & 106 \\
\hline $\mathrm{MoS}_{2}$ sheet $[8]$ & 200 & - & 104 & 59 \\
\hline Double-gyroid $\mathrm{MoS}_{2}$ films [34] & 0.7 & - & $\sim 235$ & 50 \\
\hline $\mathrm{MoO}_{3}-\mathrm{MoS}_{2}$ nanowires [35] & - & $\begin{array}{l}20 \text { (iR corrected) } \\
\eta=270 \mathrm{mV}\end{array}$ & 320 & $50 \sim 60$ \\
\hline $\mathrm{MoS}_{2.7} @ N P G[36]$ & - & - & 210 & 41 \\
\hline
\end{tabular}
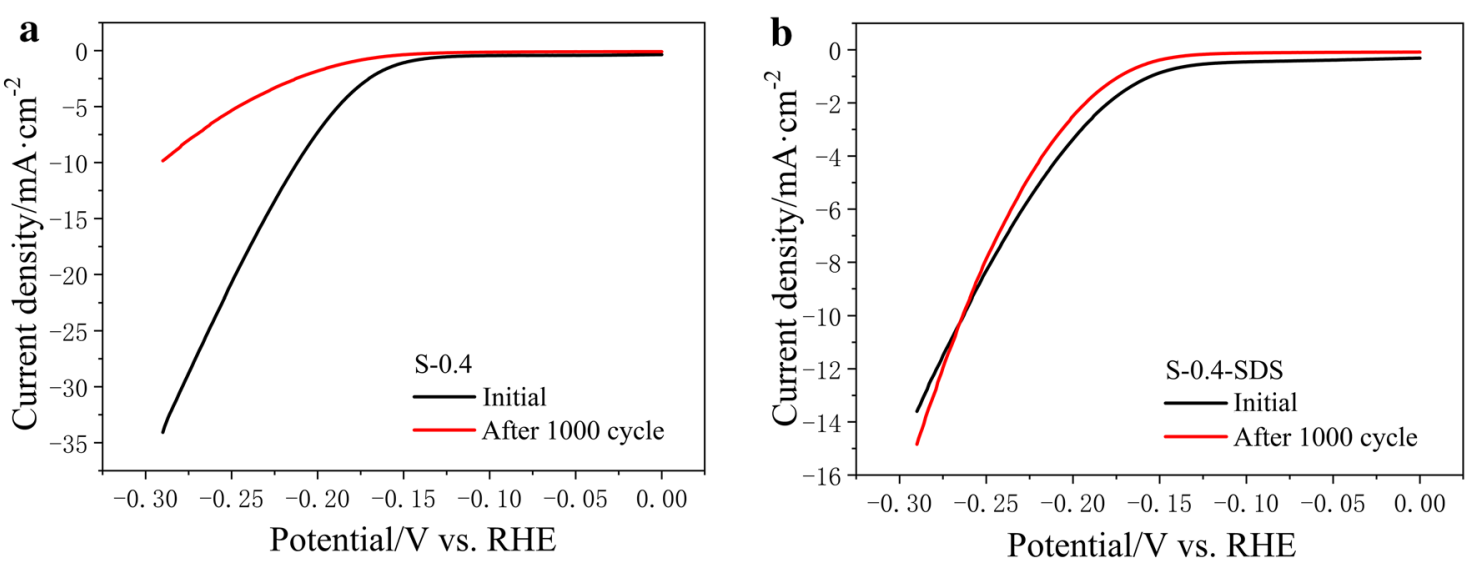

Fig. 4 a The polarization curves of S- 0.4 before and after $\mathrm{CV}$ for 1000 cycles in $0.5 \mathrm{M} \mathrm{H}_{2} \mathrm{SO}_{4}$ solution. $\mathbf{b}$ The polarization curves of S-0.4-SDS before and after $\mathrm{CV}$ for 1000 cycles in $0.5 \mathrm{M} \mathrm{H}_{2} \mathrm{SO}_{4}$ solution

degradation from $20.72 \mathrm{~mA} \mathrm{~cm}{ }^{-2}$ to $5.34 \mathrm{~mA} \mathrm{~cm}^{-2}$ (ca. $26 \%$ retention) after 1000 cycles. This suggests that the sample of S-0.4 was not stable enough. To improve the stable of the sample, a little surfactant was added into the thiomolybdates solution electrolyte. The purpose is to reduce the surface tension of the electrode, and allows the deposited sample to have better adhesion. Among a wide variety of surfactants, sodium dodecyl sulfate (SDS) was accepted. The concentration of SDS in the thiomolybdates solution was $5 \mathrm{mM}$. With the same condition of $\mathrm{S}-0.4$, the sample added SDS labeled as S-0.4-SDS. And the cathodic polarization curves were collected of the sample S-0.4-SDS shown in Fig. 4b. From the curves, the current density (without $i \mathrm{R}$ correction at overpotential of $250 \mathrm{mV}$ ) degradation from 8.31 to $7.87 \mathrm{~mA} \mathrm{~cm}^{-2}$ (ca. 95\% retention) after 1000 cycles. This demonstrates that the S-0.4-SDS films are stable throughout long-term repeated cycling in acidic electrolyte. The HER catalytic activity of the sample of S-0.4-SDS was studied by polarization measurements. The current densities are 0.86, 3.37 and $8.31 \mathrm{~mA} \mathrm{~cm}^{-2}$ at $\eta=150,200$ and $250 \mathrm{mV}$, respec-

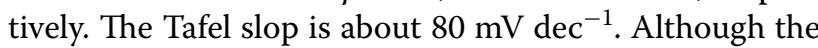
Tafel slop was higher, the stable of the catalytic was much more improved. Furthermore, SEM images performed on the two samples (Fig. 5) both of their before and after cycles. The SEM images confirms that the surface 

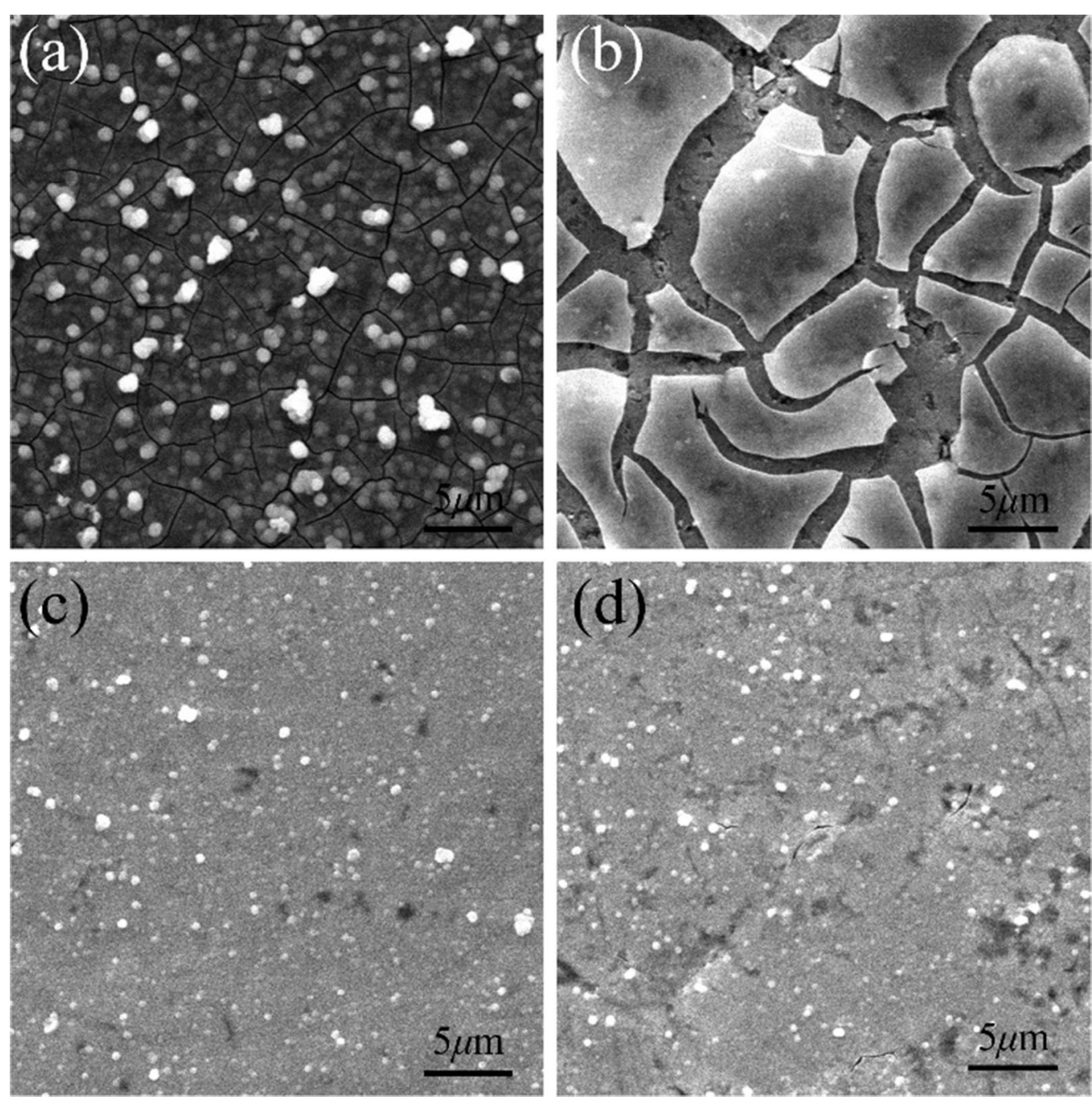

Fig. 5 SEM images of amorphous MoSx films. Panels $a$ and $b$ are the SEM images for S- 0.4 a before and $\mathbf{b}$ after CV for 1000 cycles. Panels $\mathrm{c}$ and $d$ are the SEM images for S-0.4-SDS $\mathbf{c}$ before and $\mathbf{d}$ after CV for 1000 cycles

morphology of S-0.4-SDS (Fig. 5c) and was not changed after 1000 cycles (Fig. 5d). In addition, the energy-dispersion X-ray spectroscopy (EDS) images (Additional file 1: Figure S3h, i, k, l) showed homogeneous distribution of Mo and S elements. But the surface morphology of S-0.4 (Fig. 5a) was appeared many deep cracks after 1000 cycles (Fig. 5b) with corresponding EDS mapping (Additional file 1: Figure S3b, c, e, f) uniform distribution for Mo and S elements. The SDS is one of the surface active agent. Adding appropriate surfactant can decrease the surface tension of the MoSx film, increase the dispersion and minish effectively particle size of MoSx film, thereby improve effectively the stability of the MoSx film.

Meanwhile, electrochemical impedance spectroscopy (EIS) was employed to evaluate the conductivity of the catalysts (Additional file 1: Figure S2). The Nyquist plots were fitted using an equivalent circuit containing a resistor (Rs) in series with two parallel units, a chargetransfer resistance (Rct) and a constant phase element (CPE1), where Rs represents the solution resistance. The Rs values of S-0.4, S-0.4-SDS, and $\mathrm{Ti}$ ingot are 1.546, 1.477 and $1.146 \Omega$, respectively. The observed semicircle is mainly ascribed to the Rct of $\mathrm{H}^{+}$reduction at the electrode-electrolyte interface. The Rct values of S-0.4, S-0.4-SDS, and Ti ingot are estimated as $1.762,1.941$ and $47.600 \Omega$ from the diameter of the semicircles, respectively. A smaller Rct value represents a faster reaction rate in the catalytic process. The EIS results could further explain the S-0.4 and S-0.4-SDS presented a charge-transfer resistance (Rct) obviously lower than those of $\mathrm{Ti}$ ingot. The result is consistent with the polarization curve. 


\section{Conclusions}

In conclusion, we have developed a low-cost, environmentally friendly and a simple synthetic strategy to synthesis of thiomolybdates solution as the electrolyte to electrodeposit of amorphous molybdenum sulfide thin film for the HER. Our results provide evidence for electrodeposit of amorphous molybdenum sulfide thin film not only can used the electrolyte consists purity $\left(\mathrm{MoS}_{4}\right)^{2-}$ ion but also the $\left(\mathrm{MoO}_{2} \mathrm{~S}_{2}\right)^{2-}$ ion and the $\left(\mathrm{MoOS}_{3}\right)^{2-}$ ion consists in the electrolyte can electrodeposit the amorphous molybdenum sulfide thin film. The electrolyte contained $\left(\mathrm{MoO}_{2} \mathrm{~S}_{2}\right)^{2-}$ ion and $\left(\mathrm{MoOS}_{3}\right)^{2-}$ ion electrodeposit the $\mathrm{MoS}_{\mathrm{x}}$ thin film displays a relatively high activity for HER with low overpotential of $211 \mathrm{mV}$ at a current density of $10 \mathrm{~mA} \mathrm{~cm}{ }^{-2}$, a relatively high current density of $21.03 \mathrm{~mA} \mathrm{~cm}^{-2}$ at $\eta=250 \mathrm{mV}$, a small Tafel slope of $55 \mathrm{mV} \mathrm{dec}^{-1}$. When the SDS is added into the electrolyte, the stability of the $\mathrm{MoS}_{\mathrm{x}}$ film has effectively improved, even though the catalytic activity for hydrogen evolution reaction has reduced. Therefore, this work essentially offers an economy, mild condition, viable and scalable strategy for preparing highly efficient HER electrocatalysts for the development of effective electrochemical watersplitting technology.

\section{Additional file}

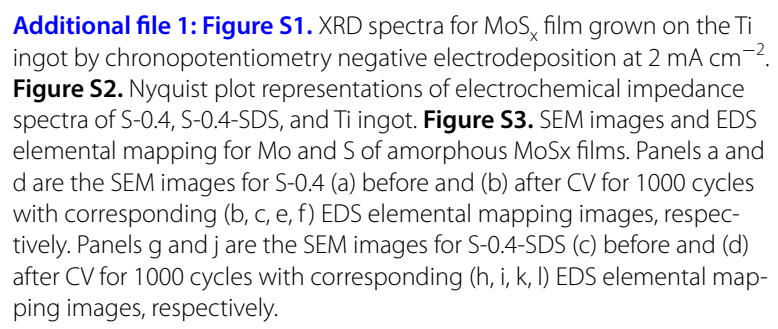

\section{Abbreviations}

MoS $_{x}$ amorphous molybdenum sulfide; HER: hydrogen evolution reaction; $C P$ : chronopotentiometry; CV: cyclic voltammograms; LSV: linear sweep voltammetry; SCE: saturated calomel electrode; RHE: reversible hydrogen potential; EIS: electrochemical impedance spectroscopy; XRD: X-ray diffractometer; SEM: scanning electron microscopy; EDS: energy dispersive $X$-ray spectroscopic; CHI: electrochemical workstation; XPS: X-ray photoelectron spectroscopy; SDS: sodium dodecyl sulfate; PTFE: polytetrafluoroethylene.

\section{Authors' contributions}

This study is an outcome of constructive discussion with LNZ and JLL. LNZ, LLW and JL carried the literature study, performed a part of the syntheses of electrolyte. LNZ was the principle investigator of the project, performed the UV-VIS Spectrophotometer, XRD, XPS, SEM, EIS and HER analyzes, discussing the result, and revised the manuscript. All authors read and approved the final manuscript.
Funding and Acknowledgments

This work was supported by the Project No. CDJXS11221171 Supported by the Fundamental Research Funds for the Central Universities, and the sharing fund of Chongqing University's Large-scale Equipment.

\section{Availability of data and materials}

We have presented all our main data in the form of tables and figures.

\section{Competing interests}

The authors declare that they have no competing interests.

Received: 16 November 2018 Accepted: 29 June 2019

Published online: 10 July 2019

\section{References}

1. Dresselhaus MS, Thomas IL (2001) Alternative energy technologies. Natute 414:332-337

2. Turner JA (2004) Sustainable hydrogen production. Science 305(5686):972-974

3. Bloor LG, Molina PI, Symes MD, Cronin L (2014) Low pH electrolytic water splitting using earth-abundant metastable catalysts that self-assemble in situ. J Am Chem Soc 136(8):3304-3311

4. Rausch B, Symes MD, Chisholm G, Cronin L (2014) Decoupled catalytic hydrogen evolution from a molecular metal oxide redox mediator in water splitting. Science 345(6202):1326-1330

5. Wang J, Xu F, Jin H, Chen Y, Wang Y (2017) Non-noble metal-based carbon composites in hydrogen evolution reaction: fundamentals to applications. Adv Mater 29(14):1605838

6. Subbaraman R, Tripkovic D, Strmcnik D, Chang KC, Uchimura M, Paulikas AP, Stamenkovic V, Markovic NM (2011) Enhancing hydrogen evolution activity in water splitting by tailoring $\mathrm{Li}^{+}-\mathrm{Ni}(\mathrm{OH})_{2}-$ Pt interfaces. Science 334(6060):1256-1260

7. Jiang B, Yang L, Liao F, Sheng M, Zhao H, Lin H, Shao M (2017) A stepwisedesigned Rh-Au-Si nanocomposite that surpasses Pt/C hydrogen evolution activity at high overpotentials. Nano Res 10(5):1749-1755

8. Hu J, Huang B, Zhang C, Wang Z, An Y, Zhou D, Lin H, Leung MKH et al (2017) Engineering stepped edge surface structures of $\mathrm{MoS}_{2}$ sheet stacks to accelerate the hydrogen evolution reaction. Energy Environ Sci 10(2):593-603

9. Jaramillo TF, Jørgensen KP, Bonde J, Nielsen JH, Horch S, Chorkendorff I (2007) Identification of active edge sites for electrochemical $\mathrm{H}_{2}$ evolution from $\mathrm{MoS}_{2}$ nanocatalysts. Science 317:100-102

10. Voiry D, Salehi M, Silva R, Fujita T, Chen M, Asefa T, Shenoy VB, Eda G et al (2013) Conducting $\mathrm{MoS}_{2}$ nanosheets as catalysts for hydrogen evolution reaction. Nano Lett 13(12):6222-6227

11. Vrubel H, Merki D, Hu X (2012) Hydrogen evolution catalyzed by $\mathrm{MoS}_{3}$ and $\mathrm{MoS}_{2}$ particles. Energy Environ Sci 5(3):6136-6144

12. Maijenburg AW, Regis M, Hattori AN, Tanaka H, Choi KS, ten Elshof JE (2014) $\mathrm{MoS}_{2}$ nanocube structures as catalysts for electrochemical $\mathrm{H}_{2}$ evolution from acidic aqueous solutions. ACS Appl Mater Interfaces 6(3):2003-2010

13. Morales-Guio CG, Hu X (2014) Amorphous molybdenum sulfides as hydrogen evolution catalysts. Acc Chem Res 47(8):2671-2681

14. Li H, Tsai C, Koh AL, Cai L, Contryman AW, Fragapane AH, Zhao J, Han HS et al (2016) Activating and optimizing MoS, basal planes for hydrogen evolution through the formation of strained sulphur vacancies. Nat Mater 15(1):48-53

15. Li G, Zhang D, Qiao Q, Yu Y, Peterson D, Zafar A, Kumar R, Curtarolo S et al (2016) All the catalytic active sites of $\mathrm{MoS}_{2}$ for hydrogen evolution. J Am Chem Soc 138(51):16632-16638

16. Kong Q, Wang X, Tang A, Duan W, Liu B (2016) Three-dimensional hierarchical $\mathrm{MoS}_{2}$ nanosheet arrays/carbon cloth as flexible electrodes for high-performance hydrogen evolution reaction. Mater Lett 177:139-142

17. Zhao Y, Xie X, Zhang J, Liu H, Ahn HJ, Sun K, Wang G (2015) $\mathrm{MoS}_{2}$ nanosheets supported on 3D graphene aerogel as a highly efficient catalyst for hydrogen evolution. Chemistry 21(45):15908-15913 
18. Hinnemann B, Moses PG, Bonde J, Jørgensen KP, Nielsen JH, Horch S, Chorkendorff I, Nørskov JK (2005) Biomimetic hydrogen evolution: $\mathrm{MoS}_{2}$ nanoparticles as catalyst for hydrogen evolution. J Am Chem Soc 127:5308-5309

19. Xie J, Zhang J, Li S, Grote F, Zhang X, Zhang H, Wang R, Lei Y et al (2013) Controllable disorder engineering in oxygen-incorporated $\mathrm{MoS}_{2}$ ultrathin nanosheets for efficient hydrogen evolution. J Am Chem Soc 135(47):17881-17888

20. Li Y, Wang H, Xie L, Liang Y, Hong G, Dai H (2011) MoS, nanoparticles grown on graphene: an advanced catalyst for the hydrogen evolution reaction. J Am Chem Soc 133(19):7296-7299

21. Merki D, Fierro S, Vrubel H, HuX (2011) Amorphous molybdenum sulfide films as catalysts for electrochemical hydrogen production in water. Chem Sci 2(7):1262-1267

22. Chang YH, Lin CT, Chen TY, Hsu CL, Lee YH, Zhang W, Wei KH, Li LJ (2013)

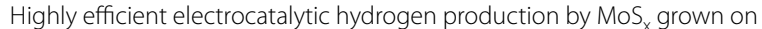
graphene-protected 3D Ni foams. Adv Mater 25(5):756-760

23. Benck JD, Chen Z, Kuritzky LY, Forman AJ, Jaramillo TF (2012) Amorphous molybdenum sulfide catalysts for electrochemical hydrogen production: insights into the origin of their catalytic activity. ACS Catal 2(9):1916-1923

24. Murugesan S, Akkineni A, Chou BP, Glaz MS, Bout DAV, Stevenson KJ (2013) Room temperature electrodeposition of molybdenum sulfide for catalytic and photoluminescence applications. ACS Nano 7(9):8199-8205

25. Vrubel H, Hu X (2013) Growth and activation of an amorphous molybdenum sulfide hydrogen evolving catalyst. ACS Catal 3(9):2002-2011

26. Albu-Yaron A, Levy-Clement C, Katty A, Bastide S, Tenne R (2000) Infulence of the electrochemical deposition parameters on the microstructure of $\mathrm{MoS}_{2}$ thin films. Thin Solid Films 361-362:223-228

27. Lamouchi A, Ben Assaker I, Chtourou R (2017) Effect of annealing temperature on the structural, optical, and electrical properties of $\mathrm{MoS}_{2}$ electrodeposited onto stainless steel mesh. J Mater Sci 52:4635-4646

28. Ponomarev EA, Neumann-Spallart M, Hodes G, Lévy-Clément C (1996) Electrochemical deposition of $\mathrm{MoS}_{2}$ thin films by reduction of tetrathiomolybdate. Thin Solid Films 280:86-89
29. Kriiss G (1884) Ueber die Schwefelverbidungen des Molybdäns. Ann Chem 225:1-57

30. McDonald JW, Friesen GD, Rosenhein LD, Newton WE (1983) Syntheses and characterization of ammonium and tetraalkylammonium thiomolybdates and thiotungstates. Inorg Chim Acta 72:205-210

31. Tran PD, Tran TV, Orio M, Torelli S, Truong QD, Nayuki K, Sasaki Y, Chiam SY et al (2016) Coordination polymer structure and revisited hydrogen evolution catalytic mechanism for amorphous molybdenum sulfide. Nat Mater 15(6):640-646

32. Pentland N, Bockris JOM, Sheldon E (1957) Hydrogen evolution reaction on copper, gold, molybdenum, palladium, rhodium, and iron: mechanism and measurement technique under high purity conditions. J Electrochem Soc 104(3):182-194

33. Chialvo MRGD, Chialvo AC (1994) Hydrogen evolution reaction: analysis of the Volmer-Heyrovsky-Tafel mechanism with a generalized adsorption model. J Electroanal Chem 372:209-223

34. Kibsgaard J, Chen Z, Reinecke BN, Jaramillo TF (2012) Engineering the surface structure of $\mathrm{MoS}_{2}$ to preferentially expose active edge sites for electrocatalysis. Nat Mater 11(11):963-969

35. Chen Z, Cummins D, Reinecke BN, Clark E, Sunkara MK, Jaramillo TF (2011) Core-shell $\mathrm{MoO}_{3}-\mathrm{MoS}_{2}$ nanowires for hydrogen evolution: a functional design for electrocatalytic materials. Nano Lett 11(10):4168-4175

36. Ge X, Chen L, Zhang L, Wen Y, Hirata A, Chen M (2014) Nanoporous metal enhanced catalytic activities of amorphous molybdenum sulfide for high-efficiency hydrogen production. Adv Mater 26(19):3100-3104

\section{Publisher's Note}

Springer Nature remains neutral with regard to jurisdictional claims in published maps and institutional affiliations.
Ready to submit your research? Choose BMC and benefit from:

- fast, convenient online submission

- thorough peer review by experienced researchers in your field

- rapid publication on acceptance

- support for research data, including large and complex data types

- gold Open Access which fosters wider collaboration and increased citations

- maximum visibility for your research: over $100 \mathrm{M}$ website views per year

At BMC, research is always in progress.

Learn more biomedcentral.com/submissions 